\title{
OPEN Evolved Fusarium oxysporum laccase expressed in Saccharomyces cerevisiae
}

\author{
Natalia Kwiatos ${ }^{1}$, Marzena Jędrzejczak-Krzepkowska ${ }^{1}$, Agnieszka Krzemińska ${ }^{2}$, \\ Azar Delavari ${ }^{3}$, Piotr Paneth ${ }^{4} \&$ Stanisław Bielecki ${ }^{1 *}$
}

Fusarium oxysporum laccase was functionally expressed in Saccharomyces cerevisiae and engineered towards higher expression levels and higher reactivity towards 2,6-dimethoxyphenol, that could be used as a mediator for lignin modification. A combination of classical culture optimization and protein engineering led to around 30 times higher activity in the culture supernatant. The winner mutant exhibited three times lower $\mathrm{Km}$, four times higher kcat and ten times higher catalytic efficiency than the parental enzyme. The strategy for laccase engineering was composed of a combination of random methods with a rational approach based on $\mathrm{QM} / \mathrm{MM}$ MD studies of the enzyme complex with 2,6-dimethoxyphenol. Laccase mediator system with 2,6-dimethoxyphenol caused fulvic acids release from biosolubilized coal.

Laccases are oxidoreductases that catalyze the 4-electron reduction of $\mathrm{O}_{2}$ to water with simultaneous oxidation of organic substrates. Laccases are able to catalyze oxidation of a substrate of interest directly or indirectly by the formation of a radical, which then may take part in a non-enzymatic event that effects in the oxidation of a substrate of interest. Laccases oxidize phenolic substrates but are also able to oxidize non-phenolic or bigger substrates by Laccase Mediator System (LMS), where a small phenolic compound acts as a mediator ${ }^{1}$. Laccases contain 4 copper atoms buried in their $3 \mathrm{D}$ structure, which are located in two separate $\mathrm{Cu}$ centers. $\mathrm{T} 1$ copper ion is a mononuclear center, whereas T2 copper ion and two T3 copper ions are positioned in T2/T3 copper center. The substrate is oxidized closed to T1 copper ion and then the electrons are transferred to the tri-nuclear center where $\mathrm{O}_{2}$ is reduced to water. The coppers are coordinated by nearby located residues: the T1 copper ion by one Cys and two His residues, the T2 copper by two His residues and a solvent molecule and T3 copper to three His residues ${ }^{2,3}$.

Biosolubilization of brown coal is a clean coal technology that aims at the conversion of the lignite to its cleaner form or to change its structure to gain new features ${ }^{4,5}$. Such solubilized material could be used as a source of value-added products ${ }^{4}$. The liquid form of coal - microorganisms, such as Fusarium oxysporum reported before as an excellent coal solubilizer ${ }^{6}$, uses their metabolites, alkaline substances, biosurfactants and enzymes to turn the solid polymer to black liquid. Laccases, from bacteria and fungi, for example from species Pleurotus ${ }^{7}$ or Streptomyces 8 , are known to take part in the degradation of lignin and lignite. These two polymers are similar in structure, thus, the mechanism of their degradation is expected to be the same. Lignin comprises only $10-20 \%$ of phenolic subunits. In theory, laccase could act on those subunits present on the lignin surface and modify the polymer. However, the possibility of lignin subunits entering the laccase active site is very limited. Moreover, it is not known to what extent lignin could be modified in this way ${ }^{9}$. According to literature data, the treatment of lignin with sole laccase leads to polymerization instead of depolymerization ${ }^{9,10}$. However, the treatment of lignin with LMS could lead the reaction in both directions depending on reaction conditions, the polymer, and the products of the first cycles of reactions ${ }^{9}$. Nevertheless, the structure of lignin promotes polymerization. The higher the redox potential of a substrate the more probable it is that laccase tends to polymerize instead of depolymerize. Due to the abundance of many phenolic subunits of lignin, polymerization may be an energetically favorable event. The degradation of lignin by LMS is still a challenge.

In this article, we report F. oxysporum Gr2 laccase functional expression in Saccharomyces cerevisiae and its engineering. The substrate scope of this enzyme was studied with docking and molecular simulations techniques.

${ }^{1}$ Institute of Technical Biochemistry, Faculty of Biotechnology and Food Sciences, Lodz University of Technology, Stefanowskiego 4/10, 90-924, Lodz, Poland. Institute of Physics, Lodz University of Technology, Wólczańska 219, 90924, Lodz, Poland. ${ }^{3}$ Independent scholar, Tehran, Iran. ${ }^{4}$ Institute of Applied Radiation Chemistry, Faculty of Chemistry, Lodz University of Technology, Wróblewskiego 15, 93-590, Lodz, Poland. *email: stanislaw.bielecki@p.lodz.pl 


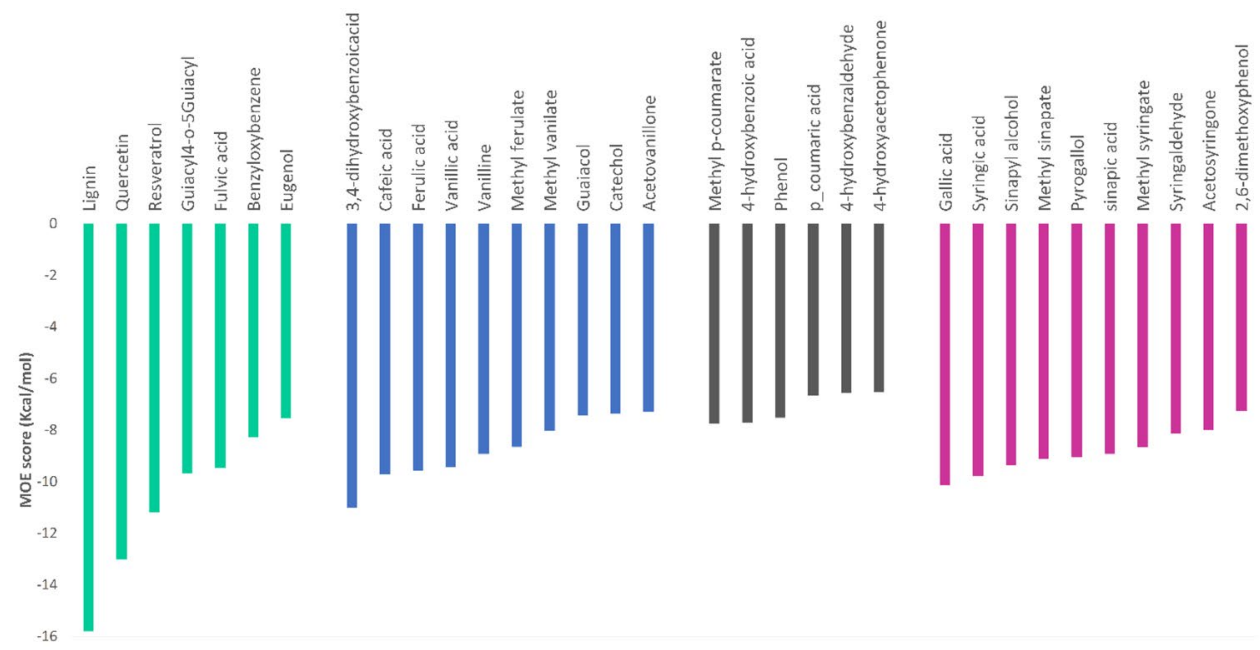

Figure 1. Docking results. Purple - syringyl derivatives of lignin, grey - p-hydroxyphenol derivatives of lignin, blue - guaiacyl derivatives of lignin, green - other potential laccase substrates.

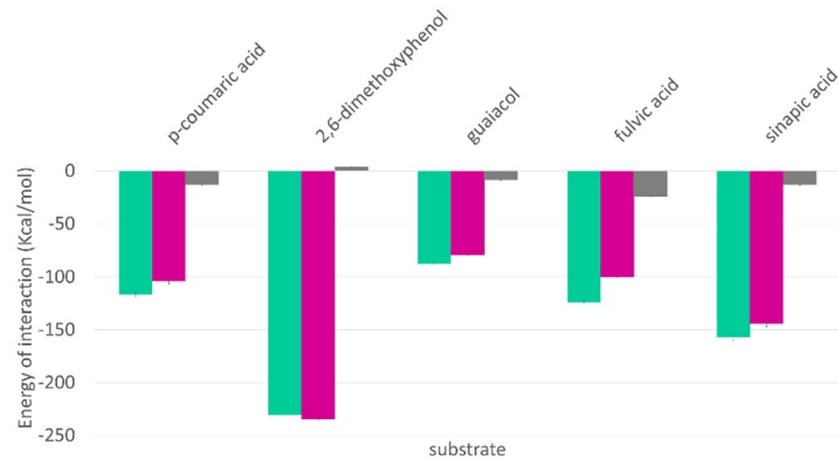

Figure 2. The interaction energy results. Grey - van der Waals energy, purple - electrostatics, green - summary energy of interaction.

S. cerevisiae strain enables easy genetic manipulations and convenient protocol for directed evolution of expressed proteins. These features were used in laccase mutagenesis towards higher activity towards 2,6-dimethoxyphenol (DMP) which can act as laccase mediator in brown coal degradation. The winner mutant was purified and characterized. Moreover, the impact of the laccase variants on solubilized coal was assessed.

\section{Results and Discussion}

Molecular simulation studies. Molecular simulation studies aimed to find a suitable substrate for Gr2 laccase. The substrate would play the role of a mediator in the LMS for brown coal biosolubilization. Homology models were used in docking studies previously with success ${ }^{11-14}$. To our knowledge, there were only two studies concerning laccase docking with multiple substrates ${ }^{11,13}$. The authors of the first one aimed to study laccases from Yersinia enerocolitica in terms of their affinity to 10 different substrates and proved that guaiacol, lignin monomers and ABTS are, among others, true substrates of the enzyme ${ }^{13}$. Another study characterized isoenzymes of Ganoderma sp. laccase and revealed that the enzymes have a higher affinity to ABTS than to lignin derived phenols ${ }^{11}$. In our study, 33 docked complexes were obtained and five of them were further analyzed. The substrates were chosen on the bases of literature search ${ }^{15-18}$. Guaiacol, $p$-coumaric acid, sinapic acid (SA), fulvic acid and DMP were selected according to the best MOE docking score (Supplemental Table S1), economic and feasibility analysis of the use of such a compound in LMS (Fig. 1).

In the next steps, obtained complexes were subjected to $1 \mathrm{~ns}$ of QM/MM MD simulations in order to study protein-ligand interactions. The energies of interactions were calculated for over 1000 structures for each complex. Figure 2 shows the summary energy of interactions for each enzyme-substrate pair and demonstrates if the energies are due to electrostatic or van der Waals interactions. The lowest energy was observed for DMP, a syringyl lignin derivative, which means the highest affinity of the enzyme to these substrates. Syringyl derivatives possess two methoxy groups on a phenol ring and this may be the reason for the lowest energy of interaction. Methoxy groups may cause stronger interaction between the residues in the binding site and themselves, which is visible in the low energy of interaction calculated for the residues closest to the ligand. 


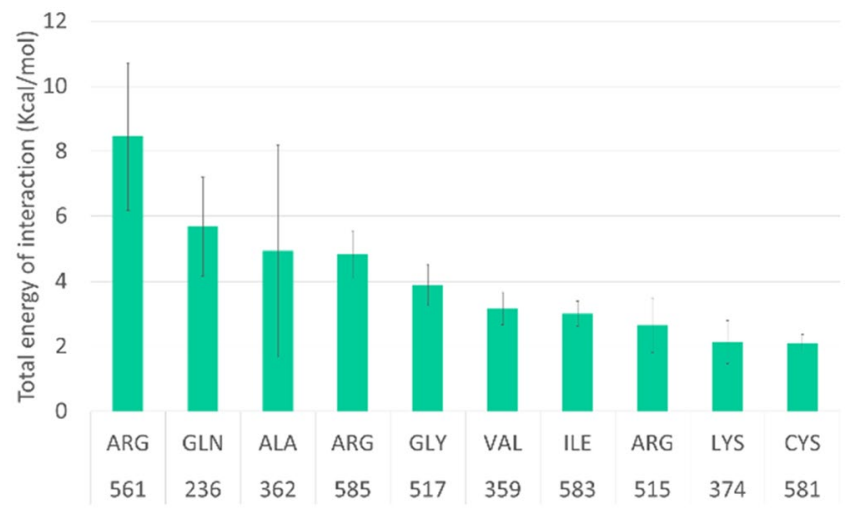

Figure 3. First ten residues with the highest energy of activation.

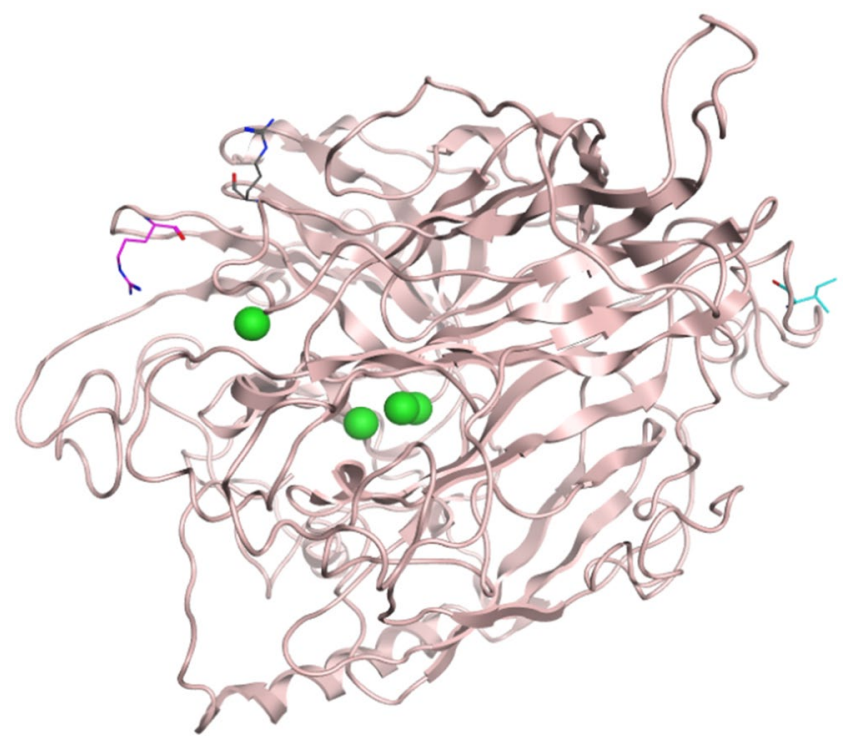

Figure 4. Position of mutated residues on Gr2 laccase model. Cyan sticks- Ile52, pink sticks Arg515, grey sticks- Arg561, green spheres - copper atoms.

The complex of laccase with DMP was subjected to deeper studies of protein-ligand interactions. As a result, a list of the energy of interactions of each laccase residue with the substrate was obtained. Figure 3 presents the first 10 residues with the highest energy - residues that may disturb substrate binding. These residues were treated as hot spots for enzyme evolution.

Expression and engineering of laccase. The vector for expression of laccase in S. cerevisiae was constructed successfully and the level of expression was checked in 96-well plate format. The average activity of laccase after the cultivation of recombinant S. cerevisiae on MEM medium was $20 \mathrm{U} / \mathrm{L}$ (ABTS assay, pH 3).

The laccase was subjected to protein engineering in order to enhance its expression and its activity towards a redox mediator (DMP) that would improve brown coal modification by the enzyme. $\mathrm{pH} 5$ was chosen as a condition for screening, as most processes of bioconversion of lignocellulose prefer $\mathrm{pH} 5$ and the new laccase could find then application not only in brown coal biodegradation but also in biorefinery development ${ }^{18-21}$.

The successful winner of the first round of evolution (error-prone PCR), 4C1 mutant, contained Ile at position 52 instead of Thr and it exhibited 6 times higher activity. The similar increase in activity towards both substrates suggests that the reason for such success lies in the more effective expression of the protein. The amino acid lies on the surface of the protein (Fig. 4), far from the catalytic center of the enzyme and co-creates a loop. This mutation may cause the formation of a new hydrogen bond between Gly51 and Thr52. Mutations on the surface of an enzyme have been discussed before as those that may influence the stability of the enzyme. For example, in the study of $P$. cinnabarinus laccase, a mutation that was introduced on the surface of the protein is claimed to enhance the flexibility of the enzyme, as the existing hydrogen bonds were broken. The authors theorized that these may have facilitated the folding of the protein in the posttranslational phases. Another mutation on that enzyme's surface caused the formation of new hydrogen bonds. Both of them contributed to enhancing the activity of this laccase ${ }^{22}$. Another example is the mutagenesis of Ala to Thr at position 361 in high redox potential laccase from basidiomycete PM1. This mutation caused the formation of an additional hydrogen bond with 

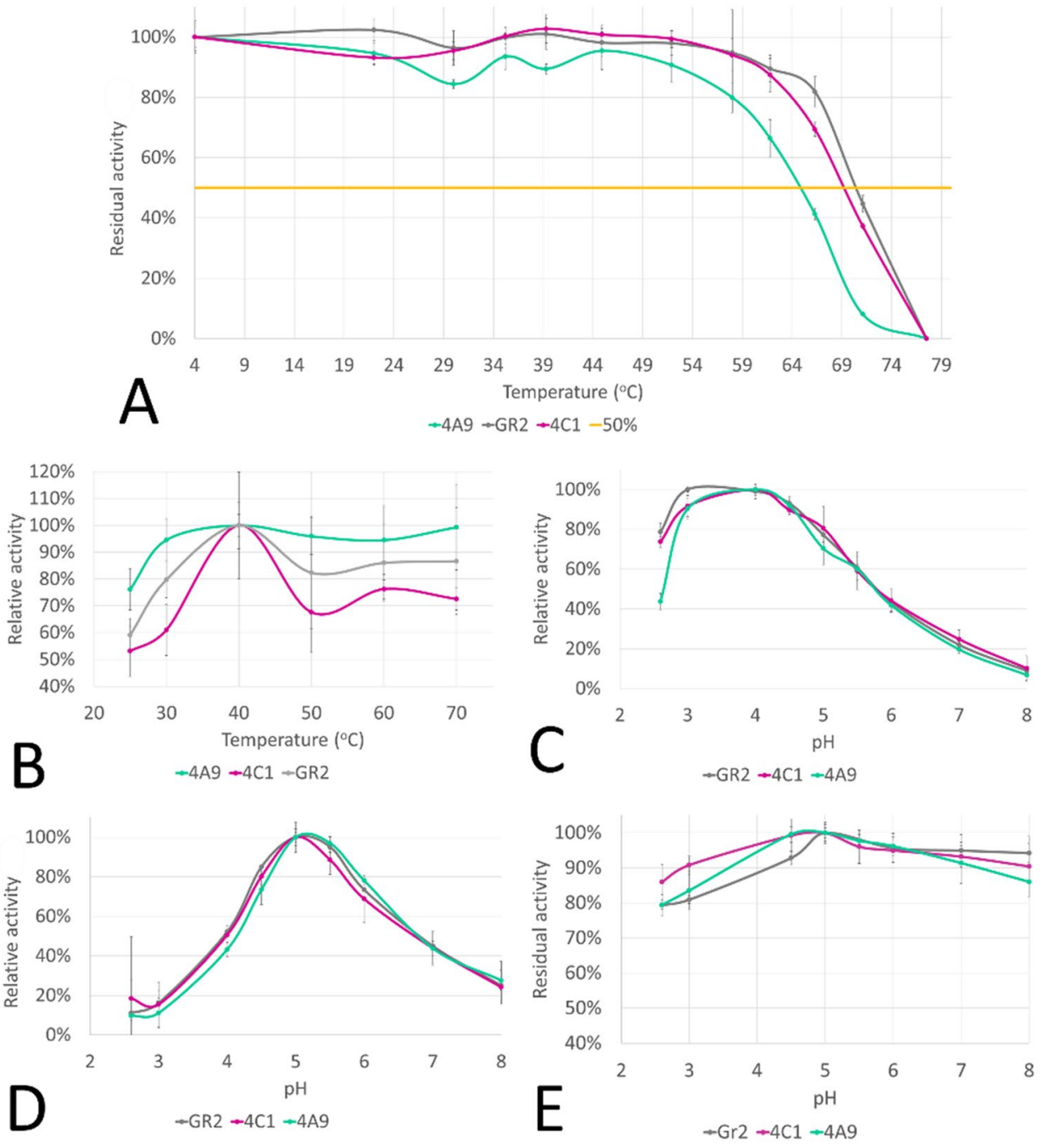

Figure 5. Characterization of $4 \mathrm{~A} 9$ laccase mutant variant: (A) thermostability profiles, (B) activity in temperature, $(\mathbf{C})$ activity in $\mathrm{pH}$ for ABTS, (D) activity in $\mathrm{pH}$ for DMP, (E) stability in $\mathrm{pH}$.

Ser372 and according to the authors strengthen the rigidity of the enzyme ${ }^{23}$. If we compare the thermostability of Gr2 laccase with 4C1 mutant (Fig. 5A), we may notice that there is not much difference. Although Ile52Thr mutation did not increase the stability, this feature was not significantly disturbed, which is often the case in directed evolution studies ${ }^{24}$.

It was shown before that the evolution of peptide sequences enhances the expression of proteins by improvement in secretion. It was believed that each protein should have its own designed signal peptide, as the mutations are somehow correlated with the target sequence. In order to use the evolved peptide for another protein, the sequences should be very similar ${ }^{25}$. Pioneering work of Wittrup's group ${ }^{26}$ suggested that evolved signal peptides could be used for the expression of various groups of proteins. Hence, it was decided to use three alpha factor pre-pro leader that were evolved and described before ${ }^{25,26}$ in order to enhance the secretory levels of $4 \mathrm{C} 1$ laccase mutant. Wit signal peptide led to the highest expression level in our experiment (Fig. 6). The results are surprising due to the fact that originally, this signal peptide was evolved for an antibody.

Alpha factor pre-pro leader has three sites for cleavage by KEX2, KEX1 and STE13 proteases. In the case of overexpressed proteins, there is a concern of the inefficient processing of peptide by STE13 protease. The amount of the protease may be insufficient in comparison to the amount of expressed enzyme. As a consequence, it was observed before that the expressed protein obtain an extra EAEA peptide on its N-termini, which in many cases may interfere with the activity of the target enzyme ${ }^{24}$. That is why the PM1 and Pcl signal peptides were also designed without STE13 cleavage site and tried for the enhanced secretion of 4C1 mutant. According to our results secretion of Gr2 laccase is better for PM1 and Pcl signal peptide retaining the STE13 site. However, the correlation may change with higher expression levels obtained for the laccase. Interestingly, Wit signal peptide does not obtain the STE13 site at all and the results are much better than the other peptides. The alpha factor evolved by Wittrup's group was used in further study. 


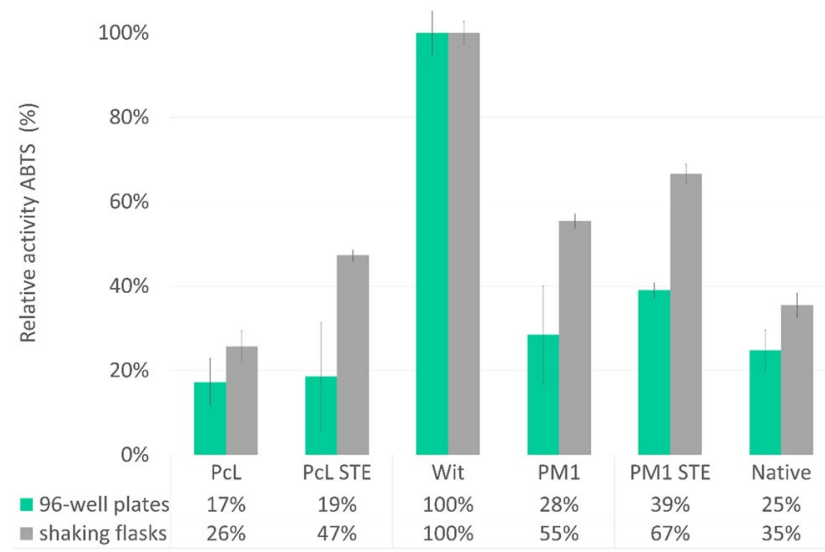

Figure 6. Laccase expression with evolved alpha factors in 96-well plates (green) and in shaking flasks (grey). The highest activity in each experiment was set to $100 \%$.

\begin{tabular}{|l|l|l|l|l|}
\hline Variant & $\mathbf{K m}(\boldsymbol{\mu M})$ & $\begin{array}{l}\text { Specific activity } \\
(\mathbf{U} / \mathbf{m g})\end{array}$ & $\mathbf{k c a t}\left(\mathbf{s}^{-1}\right)$ & $\begin{array}{l}\mathbf{k c a t} / \mathbf{K m}^{\prime} \\
\left(\mu \mathbf{M}^{-1} \mathbf{s}^{-1}\right)\end{array}$ \\
\hline ABTS & 721.8 & 6.23 & 7.48 & 0.01 \\
\hline Gr2 & 48.5 & 8.50 & 10.27 & 0.21 \\
\hline $4 \mathrm{C} 1$ & 231.6 & 35.4 & 42.71 & 0.18 \\
\hline 4A9 & \multicolumn{5}{|l}{} \\
\hline DMP & 739.0 & 10.28 & 12.34 & 0.02 \\
\hline Gr2 & 504.4 & 11.55 & 13.96 & 0.03 \\
\hline $4 C 1$ & 49.97 & 60.29 & 0.22 \\
\hline $4 A 9$ & 271.7 &
\end{tabular}

Table 1. Kinetic constants for Gr2 laccase and its mutants towards ABTS and DMP.

The improvement of the activity towards the small compound would indirectly improve brown coal modification. Gr2 laccase can catalyze the oxidation of DMP and then oxidized DMP can oxidize lignite leading to its modification. The functional hot spots given by HotSpotWizard 2.0 (Supplemental Table S2) were compared to QM/MMMD results. Two residues indicated by both methods were chosen for combinatorial mutagenesis studies Arg515 and Arg561. The 4A9 mutant was selected as the winner of the third generation of mutagenesis. The mutant exhibited 30\% higher activity towards DMP and no change of activity towards ABTS. At both positions 515 and 561 Arg was exchanged with Thr. Arg561 and Arg515 are situated on the surface of the protein (Fig. 4), in the entrance to the substrate binding site. Exchange of bulky amino acids to smaller ones was described before as a method for widening substrate binding site, thus expanding the substrate scope of the enzyme ${ }^{27,28}$. Such an approach could be beneficial for lignite modification. During the process, small phenolic substances are being created and they could act as additional laccase mediators and in this way improve the efficiency of the process. That is why Arg515 and Arg561 were chosen as the hot spot for combinatorial saturation mutagenesis by in vivo overlap extension (IVOE) $)^{29,30}$. The mutant with the highest activity was the one with a mutation to Thr at both positions. The mutation to smaller amino acid causes a change in the architecture of the area close to the entrance to the active site. Arg with long electrically charged side chains occupies more space than Thr which may disturb some substrates to enter the binding pocket (Fig. 4). The distance between Ser235 (another amino acid in the vicinity of binding site entrance) and Thr515 is longer than the distance between Ser235 to Arg515 (11.3 and $7.9 \AA$ respectively), which caused the affinity to be increased towards DMP (Table 1). Other studies described the mutation of an amino acid residue to a smaller one. For example, Tyr193 was mutated into Cys in Enterobacter cloacae esterase, which caused a decrease in the steric hindrance near the enzyme binding pocket. As a result the substrate and product could enter and exit the active site more freely ${ }^{31}$. In the study of P. chrysosporium alcohol oxidase, one of mutation of Phe313 to Leu caused a small increase in space in the cavity and the enzyme gained the possibility of converting glycerol ${ }^{28}$.

Production, purification and characterization of 4A9 laccase variant. The 4A9 mutant was produced in five $2 \mathrm{~L}$ shaking flasks and the maximum level of expression was around $600 \mathrm{U} / \mathrm{L}$. The yield of purification was $25 \%$ where $35 \mathrm{U} / \mathrm{mg}$ specific activity was reached (Supplemental Table S4, Supplemental Figs. S1 and S2).

The $4 \mathrm{~A} 9$ mutant had optimal activity at $40^{\circ} \mathrm{C}$ (Fig. 5B). $4 \mathrm{~A} 9$ mutant gained higher activity in both lower and higher temperatures compared to the native enzyme. In $25^{\circ} \mathrm{C}$, the activity of $\mathrm{Gr} 2$ was below $60 \%$, while the activity of $4 \mathrm{~A} 9$ mutant was $16 \%$ higher. Moreover, the activity of the final mutant $4 \mathrm{~A} 9$ in higher temperatures was also enhanced. Most fungal laccases have their optimal activity at higher temperatures. For example, laccase 

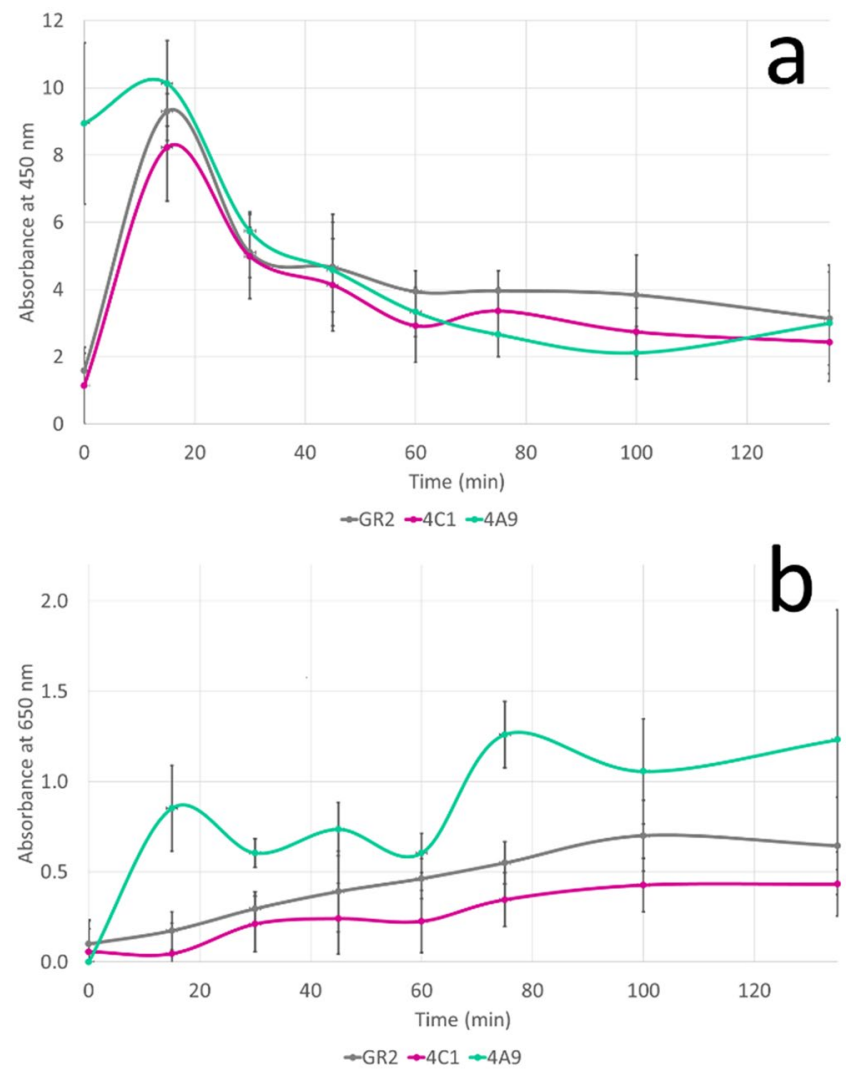

Figure 7. Changes in humic acids (a) and fulvic acids (b) presence during process of brown coal modification by laccase variants.

from Coprinopsis cinerea (basidiomycetes) at $60^{\circ} \mathrm{C}^{32}$, Pycnoporus sanguineus at $65^{\circ} \mathrm{C}^{33}$ and Melanocarpus albomyces (ascomycetes) at $60-70^{\circ} \mathrm{C}^{34}$ have their optimal activity. The thermostability of the enzymes is comparable to other laccases expressed in S. cerevisiae $\left(\mathrm{T}_{50}\right.$ around $\left.70^{\circ} \mathrm{C}\right)$ : P. cinabarinus laccase, $\mathrm{PM} 1$ laccase or T. versicolor laccase $22,35,36$ (Fig. 5A).

The activity of Gr2 laccase and its mutants was strongly related to $\mathrm{pH}$. In the case of ABTS substrate, Gr2 laccase is most active at $\mathrm{pH} 3$, while the $\mathrm{pH}$ optimum for $4 \mathrm{C} 1$ and $4 \mathrm{~A} 9$ mutants is around $\mathrm{pH} 4$ (Fig. 5C). The activity towards DMP for all variants retained 90\% activity in the range of $\mathrm{pH}$ between 3 and 4.5 (Fig. 5D). Gr2 laccase and its mutants were most stable at $\mathrm{pH}$ close to 5 (Fig. 5E). All three variants exhibit considerable and similar stability towards storage at different $\mathrm{pH}$.

Kinetic constants for Gr2 laccase and its mutants are given in Table 1. The table clearly shows the progress of protein engineering - 4C1 mutant is already an improved variant in terms of $\mathrm{Km}$ and catalytic efficiency and 4A9 mutant, the winner of the whole campaign has the lowest $\mathrm{Km}$, the highest kcat and $\mathrm{kcat} / \mathrm{Km}$. The $\mathrm{Km}$ was almost three times lower for 4A9 mutant than the Km of the parental enzyme. Although, the biochemical tests for Gr2 and $4 \mathrm{C} 1$ mutant were performed on unpurified samples and the specific activities might be unreal, the trend of catalytic improvement was kept. If one compares the kcat and $\mathrm{kcat} / \mathrm{Km}$ for all three unpurified samples, it can be noticed that both values are the highest for 4A9 mutant (not shown in the table; unpurified 4A9 exhibited kcat of $48 \mathrm{~s}^{-1}$ and catalytic efficiency of $0.2 \mu \mathrm{M}^{-1} \mathrm{~s}^{-1}$ ). The $\mathrm{Km}$ of many fungal laccases is in the range of $20-30 \mu \mathrm{M}^{36-38}$, which is 10 times lower than for 4A9 mutant. The laccase from Thielavia sp. has the turnover for DMP $3.46 \mathrm{~s}^{-1}$ and catalytic efficiency of $0.17 \mu \mathrm{M}^{-1} \mathrm{~s}^{-1}$, whereas, the laccase from another Ascomycota B. aclada has the kcat of $45.6 \mathrm{~s}^{-1}$ and $\mathrm{kcat} / \mathrm{Km}$ of $2.4 \mu \mathrm{M}^{-1} \mathrm{~s}^{-1}$. Hence, Gr2 laccase and its variants had quite high turnover numbers, however, the overall catalytic efficiency could be improved. Future protein engineering studies could focus on enhancing the affinity of the enzyme to the substrate.

Brown coal modification. Gr2 laccase is able to degrade and modify solubilized brown coal (Fig. 7) in LMS. The docking studies confirmed by biochemical studies indicated DMP to be used as a mediator for this process. In the first minutes of the process, humic acids were formed which is illustrated by an increase in absorbance at $450 \mathrm{~nm}$ (Fig. 7a). Then, the number of humic acids decreased, which could be caused by their degradation to fulvic acids (simultaneous increase in absorbance at $650 \mathrm{~nm}$ ) (Fig. 7b). 4A9 mutant produced the highest amount of fulvic acids during the same unit time as $\mathrm{Gr} 2$ and $4 \mathrm{C} 1$ laccases. Part of the products created in the process with 4A9 mutant might have become substrates for further conversions and that is why we observe an undulating curve in Fig. $7 \mathrm{~b}$ for the increase in fulvic acids amount. Other variants are less effective and this is probably the reason for the difference in the shape of the curves. Table 2 presents the increase of fulvic acids release for 


\begin{tabular}{|l|l|l|l|}
\hline Variant & Gr2 & 4C1 mutant & 4A9 mutant \\
\hline $\begin{array}{l}\text { Increase in fulvic acids } \\
\text { release during the process }\end{array}$ & $29 \%$ & $17 \%$ & $54 \%$ \\
\hline
\end{tabular}

Table 2. Increase in fulvic acid release during the process of brown coal modification in presence of 2,6-dimethoxyphenol in regard to the control - solubilized coal with the mediator.

all variants. It indicates that $4 \mathrm{~A} 9$ mutant is the most effective one - it doubles the production of fulvic acids in comparison to Gr2 laccase.

\section{Conclusions}

In this study, F. oxysporum Gr2 laccase was expressed for the first time in S. cerevisiae. The relatively low expression level was enhanced around 30 times due to a combination of protein engineering and classical culture optimization. A new enzyme was designed by random mutagenesis and site-saturation techniques supported by molecular simulation studies. The new laccase carries three mutations - Ile52Thr, Arg515Thr and Arg561Thr, which contributed to 10 times higher catalytic efficiency of the enzyme. The $4 \mathrm{~A} 9$ laccase mutant is most active at $40^{\circ} \mathrm{C}$ and loses only up to $20 \%$ activity when the reaction takes place either in higher or lower temperatures. The mutagenesis did not disturb the stability of the protein. All the above features make the mutant a very promising tool for potential industrial applications, such as brown coal solubilization of lignin modification. The efficient laccase mediator system with DMP was proposed. This paper demonstrates the first such advanced study concerning usage of laccase for lignite modification.

\section{Materials and Methods}

Materials. S. cerevisiae BJ5465 strain (ATCC 208289) used in this study was obtained thanks to the courtesy of Dr Miguel Alcalde, CSIC, Madrid. All chemicals used in the study were analytical grade and bought from Sigma-Aldrich or Chempur. The brown coal used in the study was obtained from Bełchatów Brown Coal Mine (Poland). Coal particles with a diameter of 1-2 mm were subjected to pretreatment with ozonation and then subjected to microbial solubilization as explained before ${ }^{5,39}$.

Methods. In silico studies. Preparation of Gr2 laccase model for molecular dynamics: The backbone of Gr2 laccase was made of 640 amino acids with four copper ions coordinated in an optimal position to stabilize second-order protein structure. The parameter set for the copper atoms is included in Supplemental Table S5-Table S7. Cu-L distances and L-Cu-L angles, were taken from the available DFT-optimized model structure described by Comba and Remenyi ${ }^{40}$. To maintain interactions between copper atoms and neighboring residues constraint conditions have been applied with force constant $2500 \mathrm{~kJ} /\left(\mathrm{mol}^{*} \mathrm{~A}^{2}\right)$. Force field parameters and electrostatic charges of atoms for protein were derived from the AMBER libraries [FF99SB force field] ${ }^{41}$. To confirm the protonation states of amino acids, especially His residues, the pKa values were computed by using PROPKA3. $0^{42}$ software at $\mathrm{pH}=7.0$. Hydrogen atoms were added using the tLEAP module of AMBER program ${ }^{43}$. The system was neutralized by the addition of 30 sodium cations in optimal positions indicated by AM1 calculations implemented in tLEAP. The system was soaked in the orthorhombic box of TIP3P water molecules of the size $120 \times 128 \times 120 \AA$. Afterward, energy minimization was applied to relax the whole structure by using the AMBER11 program ${ }^{44}$.

Molecular docking: The molecular docking studies were performed by using the MOE docking program ${ }^{45}$. The whole set of protein binding pocket residues were chosen for the docking site and treated flexible upon docking. The structures of 33 ligands were prepared and optimized with the MMFF94 force field ${ }^{46}$. The 30 docking runs were estimated to be efficient enough to list the possible poses. The London $\Delta \mathrm{G}$ scoring function was used to rank order of the different poses generated. Based on the obtained results, ligands: coumaric acid, DMP, fulvic acid, guaiacol, and SA were selected for further investigation and molecular dynamics studies.

Molecular dynamic studies: Parameters for the five ligands chosen were obtained using GAFF $^{47}$ from the tLEAP module. Subsequently, several optimizations and dynamic simulations for each ligand-protein complexes were performed using AMBER ff99SB ${ }^{48}$ force filed of AMBER 11 with a time step of $1 \mathrm{fs}$. Periodic boundary conditions, the particle mesh Ewald method ${ }^{49}$ and the cut-off for nonbonding interactions with a range radius from 14.5 to $16 \AA$ were applied. The systems were heated from 0 to $300 \mathrm{~K}$ with $0.001 \mathrm{~K}$ step size. Equilibration of complexes was achieved during $500 \mathrm{ps}$ of Langevin-Verlet dynamics at $300 \mathrm{~K}$. Complexes were stabilized by performing $1 \mathrm{~ns}$ of NVT MM MD. In order to study protein-ligand interactions, the $1 \mathrm{~ns}$ of QM/MM molecular dynamics simulations were performed using AMBER11, where the QM part, only ligands at this stage, was treated at the PM3 semiempirical level of theory ${ }^{41}$. VMD ${ }^{50}$ and DiscoveryStudio ver.3.5 $5^{51}$ were used for visualization of complexes.

Analysis of substrate-enzyme interactions: To study interactions between ligands and protein residues the free energy decomposition per-residue scheme has been applied as implemented in AMBER11 by using MMPBSA module ${ }^{52}$. MMPBSA is a post-processing method that requires trajectories obtained during QM/MM molecular dynamics simulations (.mdcrd file with trajectory) and allows to study specific interactions between ligand and protein residues. Hence, previously obtained trajectories from five selected ligands simulated during $1 \mathrm{~ns}$ PM3/ AMBER studies were used for further per-residue interaction analysis. Afterward, one of them was selected as the most promising structure and additional PM3/AMBER dynamics simulation was performed, with the QM part composed of the substrate, Asp293, Cys363, one copper cation, and three water molecules. Finally, the interaction analysis for the substrate treated more precisely with the bigger QM part was computed.

Vector construction and expression of Gr2 laccase: The coding sequence of Gr2 laccase (GeneBank accession number MH351668) was subjected to two PCR reactions. The first one amplified laccase coding sequence 
producing 40 nucleotide long overhangs - on the $5^{\prime}$ end homologous to $\alpha$ factor sequence and on the $3^{\prime}$ end homologous to pYES2 vector. The second reaction amplified $\alpha$ factor sequence producing overhangs - on the $5^{\prime}$ end homologous to pYES2 vector and on the $3^{\prime}$ end homologous to the laccase coding sequence. The primers and PCR conditions used are given in Supplemental Table S8. Three DNA sequences were prepared for transformation to competent $S$. cerevisiae cells: linearized with SacI and NotI purified from agarose gel pYES2 vector, $\alpha$ factor sequence and the laccase coding sequence. The sequences, $100 \mathrm{ng}$ each, were co-transformed to $S$. cerevisiae cells according to Yeast Transformation Kit (Sigma-Aldrich). The cells were grown on selective SC dropout plates for 3 days at $30^{\circ} \mathrm{C}$ at stationary conditions. We used SC medium for the cultivation of S. cerevisiae (1.92 g/l yeast synthetic dropout-medium supplement without uracil, $6.7 \mathrm{~g} / \mathrm{l}$ yeast nitrogen base without amino acids, $2 \mathrm{~g} / \mathrm{l}$ glucose or raffinose, $25 \mu \mathrm{g} / \mathrm{ml}$ chloramphenicol), YPD for the cultivation of selected clones in rescreening step ( $2 \%$ peptone from casein, $1 \%$ yeast extract, $0.4 \%$ glucose, $25 \mu \mathrm{g} / \mathrm{ml}$ chloramphenicol) and laccase minimal expression medium (MEM) with $0.2 \mathrm{mM} \mathrm{CuSO}_{4}(1.92 \mathrm{~g} / \mathrm{l}$ yeast synthetic dropout-medium supplement without uracil, $6.7 \mathrm{~g} / \mathrm{l}$ yeast nitrogen base without amino acids, $2 \mathrm{~g} / \mathrm{l}$ galactose, $25 \mu \mathrm{g} / \mathrm{ml}$ chloramphenicol $)^{24}$. The medium was inoculated by transferring a single yeast colony by a sterile toothpick. Wild-type S. cerevisiae was cultivated in the same media but with the addition of $20 \mathrm{mg} / \mathrm{L}$ uracil. Plates were sealed and put in a box with wet paper towels to prevent evaporation and cultivated for 3 days at $30^{\circ} \mathrm{C}$ and $250 \mathrm{rpm}$. Then the plates were centrifuged for $15 \mathrm{~min}$ at $1149 \times \mathrm{g}, 4^{\circ} \mathrm{C}$.

$1^{\text {st }}$ round - Error-Prone PCR: The Gr2 coding sequence was subjected to PCR with Taq polymerase with a previously set $25 \mu \mathrm{M} \mathrm{MnCl}_{2}$ end concentration (Supplemental Table S9 and S10). $100 \mathrm{ng}$ of linearized pYES2 and $150 \mathrm{ng}$ of the PCR product were co-transformed to S. cerevisiae competent cells. The colonies that grew on the selective SC dropout plates were picked and cultivated on 96-well plates in MEM for $72 \mathrm{~h}, 30^{\circ} \mathrm{C}$ and $250 \mathrm{rpm}$. Next, the screening was performed in order to choose the winner for the next round of enzyme evolution. Individual clones were selected and cultured on 96-well plates in expression medium as described above. In each plate, the $6^{\text {th }}$ column was inoculated with $S$. cerevisiae cells carrying a pYES2 plasmid with a parental type gene, while $\mathrm{H} 1$ well was inoculated with wild-type $S$. cerevisiae. The cultivation took place as explained above. Next, the plates were centrifuged $\left(1149 \times \mathrm{g}, 15 \mathrm{~min}, 4^{\circ} \mathrm{C}\right)$ and $20 \mu \mathrm{l}$ supernatant was transferred from master plates to two fresh 96 -well replica plates by pipetting machine (Hamilton). The screening of mutant libraries consisted of two assays - with ABTS or DMP. The activity was measured at $25^{\circ} \mathrm{C}$ by monitoring the oxidation of $5 \mathrm{mM}$ ABTS $\left(\varepsilon_{420}=36,000 \mathrm{M}^{-1} \mathrm{~cm}^{-1}\right)$ or $8 \mathrm{mM} \mathrm{DMP} \varepsilon_{469}=49,600 \mathrm{M}^{-1} \mathrm{~cm}^{-1}$ ) in McIlvaine buffer of $\mathrm{pH}$ 5. Next, the best mutants were subjected to first, second and third re-screening as described earlier ${ }^{22}$, in order to minimize false positive results.

$2^{\text {nd }}$ round - evolved $\alpha$ factors: Three evolved alpha factor pre-pro leaders previously described in papers were synthesized by GeneArt (Thermo Fisher Scientific) - PM1 laccase evolved alpha factor (PM1), Pycnoporus cinnabarinus laccase evolved alpha factor $(\mathrm{PcL})^{22,24}$ and alpha factor evolved by K. Dane Wittrup group at MIT, Cambridge (Wit ${ }^{26}$. The signal peptides were subjected to PCR reactions in order to obtain flanking regions homologous to the pYES2 vector at $5^{\prime}$ site and $4 \mathrm{C} 1$ laccase mutant at $3^{\prime}$ site. The $4 \mathrm{C} 1$ mutant was also subjected to PCR reaction in order to obtain a flanking region homologous with the signal peptides at $5^{\prime}$ and pYES2 vector at $3^{\prime}$ site. The PCR reactions were done with Q5 high fidelity 2x Master Mix (NEB) (Supplemental Table S11). The vector construction, transformation and cultivation were done as explained above. In this round of evolution, the screening was done differently than for other rounds of evolution. The plates were screened with ABTS assay at $\mathrm{pH} 3$ and here only the expression levels were compared (by laccase activity in culture supernatant). The level of expression was also checked for a $100 \mathrm{ml}$ flask format $\left(30^{\circ} \mathrm{C}, 220 \mathrm{rpm}\right)$.

$3^{\text {rd }}$ round - site saturation mutagenesis: In silico QM/MM MD simulations revealed the energy of interaction of each amino acid residue with laccase substrates. Those with energy higher than zero were analyzed as potential hot spots for mutagenesis. Parallelly, analysis of laccase-DMP complex model was done with HotSporWizard 2.0 software available at https://loschmidt.chemi.muni.cz/hotspotwizard/ according to the procedure explained before $^{53}$. The functional hot spots given by the program were compared to QM/MM results. Two residues indicated by both methods were chosen for combinatorial mutagenesis studies - Arg 515 and Arg 561. The library was designed with the library design tool available at HSW 2.0 website, amino acid frequencies were chosen as the mode for selection of amino acids and minimal frequency was set to 5 . The mutagenic PCR was conducted with Q5 high fidelity 2x Master Mix (Supplemental Table S12). The vector construction, transformation, cultivation and screening was performed in the same way as in the $1^{\text {st }}$ round of mutagenesis.

Production and purification: The colonies that exhibited the highest laccase activity were picked and cultivated in shaking flask format in SC Raffinose medium (galactose in MEM was exchanged with $2 \mathrm{~g} / \mathrm{L}$ raffinose and no $\mathrm{CuSO}_{4}$ was added) for $72 \mathrm{~h}$ at $30^{\circ} \mathrm{C}, 220 \mathrm{rpm}$. Next, the cultures were refreshed to $\mathrm{OD}_{600} 0.3$ and cultivated in the same conditions for $6-8 \mathrm{~h}$ till $\mathrm{OD}_{600}$ reached 1 . The main cultures were started with the addition of $10 \%$ pre-culture to the expression medium which contained $1 \mathrm{mM} \mathrm{CuSO}_{4}$. After $24 \mathrm{~h}$ of cultivation at $25^{\circ} \mathrm{C}$ and $60 \mathrm{rpm}, 10 \%$ galactose was supplemented and the cultivation was prolonged for the next $48 \mathrm{~h}$. The cells were separated by centrifugation $\left(10000 \times \mathrm{g}, 20 \mathrm{~min}, 4^{\circ} \mathrm{C}\right)$ and filtration through $0.4 \mu \mathrm{m}$ cellulose filters. Next, the culture supernatant was concentrated on $30 \mathrm{kDa}$ Sartorius Hydrosart UF $\mid$ MF Sartocon Slice 200 (Sartorius) using Sartorius tangential flow system followed by buffer exchanged to $20 \mathrm{mM}$ Bis-Tris-HCl, pH 5.9 (buffer A for cation exchange chromatography). The conductivity of the sample was adjusted to buffer A and the sample was loaded to HiPrep QFF 16/60 column (GE Healthcare) connected to an Aktä system (GE Healthcare). The protein was eluted with $55 \%$ of buffer B ( $20 \mathrm{mM}$ Bis-Tris- $\mathrm{HCl}$ with $200 \mathrm{mM} \mathrm{NaCl}, \mathrm{pH}$ 5.9). Samples with laccase activity towards ABTS at pH 5 were pulled, concentrated on Sarticon with $10 \mathrm{kDa}$ cut-off (Sartorius) with simultaneous buffer exchange to $50 \mathrm{mM}$ Na-acetate, $\mathrm{pH}$ 4.4. The sample was loaded on two HiTrap SPFF $1 \mathrm{ml}$ columns connected in a row (GE Healthcare). The protein was eluted with a linear gradient of $1 \mathrm{M} \mathrm{NaCl}$. The fractions with laccase activity towards ABTS were pulled, concentrated on Sarticon with $10 \mathrm{kDa}$ cut-off. In the last step of the purification protocol, the samples were subjected to gel filtration chromatography of Sephadex 200 column (GE Healthcare) in $50 \mathrm{mM} \mathrm{Na}$-acetate buffer of pH 5 with $150 \mathrm{mM} \mathrm{NaCl}$. The progress of the purification was 
monitored by SDS-PAGE electrophoresis on 12\% TruPage precast gels (Sigma-Aldrich) stained with Pierce Silver Stain kit (Thermo Fisher Scientific).

Characterization: Laccase variants were concentrated on centrifugal filters with $10 \mathrm{kDa}$ cut-off and subjected to characterization. The winner of the evolution was also characterized after purification. The determination of protein concentration was done according to the Bradford method with Bradford reagent (Sigma-Aldrich) according to the manufacturer's instructions. The substrate specificity of laccases was tested towards ABTS $\left(\varepsilon_{420}=36000 \mathrm{M}^{-1} \mathrm{~cm}^{-1}\right)$ and DMP $\left(\varepsilon_{469}=27500 \mathrm{M}^{-1} \mathrm{~cm}^{-1}\right)$. Appropriate laccase dilutions were prepared in such a way that $20 \mu \mathrm{l}$ aliquots produced a linear response in the kinetic mode. $\mathrm{pH}$ stability was assessed for $\mathrm{pH}$ range from 2 to 8 (assessed after $24 \mathrm{~h}$ incubation at $4^{\circ} \mathrm{C}$ ), temperature stability from 20 to $80^{\circ} \mathrm{C}(10$ minutes incubation at a given temperature and 5 minutes incubation on ice), for both characteristics ABTS assay at pH 5 was used. The optimal temperature for the activity of laccase variants was assessed with ABTS, pH profiles were done for both substrates. The kinetic constants were determined for optimal $\mathrm{pH}$ towards ABTS and DMP. Reactions were conducted for 9 different substrate concentrations in $200 \mu \mathrm{l}$ reaction volumes in McIlvaine buffer of optimal pH for the enzymes at $25^{\circ} \mathrm{C}$. Substrate oxidation was followed by measurement of absorption in kinetic mode. To calculate the values of $\mathrm{Km}$ and kcat, the average $\mathrm{V}_{\max }$ was represented versus substrate concentration and fitted to a ligand binding fit with one-site saturation in SigmaPlot (version 11.0) software. Deglycosylation of the 4A9 mutant was achieved with PNGaseF (NEB) according to the manufacturer's instructions.

Brown coal modification: The experiment studying the impact of laccase on brown coal modification was done with concentrated culture supernatants of $\mathrm{Gr} 2,4 \mathrm{C} 1$ and $4 \mathrm{~A} 9$ laccases. Firstly, brown coal pretreated by ozonation ${ }^{39}$ was solubilized by Gordonia alkanivorans S7 ${ }^{5} .200 \mu$ of coal was mixed with $100 \mu \mathrm{l} 100 \mathrm{mM}$ DMP, $300 \mu \mathrm{l}$ McIlvaine buffer $\mathrm{pH}$ 5. The reaction was started with the addition of $400 \mu \mathrm{l}$ enzyme preparation of $1.7 \mathrm{U} / \mathrm{ml}$. The control samples contained buffer instead of enzyme preparation. The $2 \mathrm{ml}$ Eppendorf tubes with the mixtures were shaken with $150 \mathrm{rpm}$ at $25^{\circ} \mathrm{C} .20 \mu \mathrm{l}$ of samples were taken during $180 \mathrm{~min}$ of the process. The samples were diluted 10 times and absorbance at $450 \mathrm{~nm}$ and $650 \mathrm{~nm}$ were measured in order to monitor the release of humic and fulvic acids.

\section{Data availability}

All data generated and/or analyzed during this study are included in this published article (and its Supplemental Information files) or are available from the corresponding author on reasonable request.

Received: 6 August 2019; Accepted: 14 January 2020;

Published online: 24 February 2020

\section{References}

1. Antošová, Z. \& Sychrová, H. Yeast hosts for the production of recombinant laccases: A review. Mol. Biotechnol. 58, 93-116 (2016).

2. Hakulinen, N. \& Rouvinen, J. Three-dimensional structures of laccases. Cell. Mol. Life Sci. 72, 857-868 (2015).

3. Pardo, I. \& Camarero, S. Laccase engineering by rational and evolutionary design. Cell. Mol. Life Sci. 72, 897-910 (2015).

4. Fakoussa, R. \& Hofrichter, M. Biotechnology and microbiology of coal degradation. Appl. Microbiol. Biotechnol. 52, 25-40 (1999).

5. Romanowska, I., Strzelecki, B. \& Bielecki, S. Biosolubilization of Polish brown coal by Gordonia alkanivorans S7 and Bacillus mycoides NS1020. Fuel Process. Technol. 131, 430-436 (2015).

6. Kwiatos, N., Jędrzejczak-Krzepkowska, M., Strzelecki, B. \& Bielecki, S. Improvement of efficiency of brown coal biosolubilization by novel recombinant Fusarium oxysporum laccase. AMB. Express 8, 133 (2018).

7. Jiao, X. et al. Systematic Analysis of the Pleurotus ostreatus Laccase Gene (PoLac) Family and Functional Characterization of PoLac2 Involved in the Degradation of Cotton-Straw Lignin. Molecules 23 (2018).

8. de Gonzalo, G., Colpa, D. I., Habib, M. H. M. \& Fraaije, M. W. Bacterial enzymes involved in lignin degradation. J. Biotechnol. 236, 110-119 (2016).

9. Munk, L., Sitarz, A. K., Kalyani, D. C., Mikkelsen, J. D. \& Meyer, A. S. Can laccases catalyze bond cleavage in lignin? Biotechnol. Adv. 33, 13-24 (2015).

10. Maijala, P. et al. Action of fungal laccases on lignin model compounds in organic solvents. J. Mol. Catal. B Enzym. 76, 59-67 (2012).

11. Kumar, A. et al. Gel-Based Purification and Biochemical Study of Laccase Isozymes from Ganoderma sp. and Its Role in Enhanced Cotton Callogenesis. Front. Microbiol. 8 (2017).

12. Saranya, R., Jayaprira, J. \& Temil Selvi, A. Purification, characterization, molecular modeling and docking study of fish waste protease. Int. J. Biol. Macromol. 118, 569-583 (2018).

13. Singh, D., Sharma, K. K., Dhar, M. S. \& Virdi, J. S. Molecular modeling and docking of novel laccase from multiple serotype of Yersinia enterocolitica suggests differential and multiple substrate binding. Biochem. Biophys. Res. Commun. 449, 157-162 (2014).

14. Zhao, M.-L., Wang, W., Nie, H., Cao, S.-S. \& Du, L.-F. In silico structure prediction and inhibition mechanism studies of AtHDA14 as revealed by homology modeling, docking, molecular dynamics simulation. Comput. Biol. Chem. 75, 120-130 (2018).

15. Sherif, M. et al. Biochemical studies of the multicopper oxidase (small laccase) from Streptomyces coelicolor using bioactive phytochemicals and site-directed mutagenesis. Microb. Biotechnol. 6, 588-597 (2013).

16. Chen, B., Diao, Z. \& Lu, H. Using the ReaxFF reactive force field for molecular dynamics simulations of the spontaneous combustion of lignite with the Hatcher lignite model. Fuel 116, 7-13 (2014)

17. Li, Z.-K. et al. Alkanolysis simulation of lignite-related model compounds using density functional theory. Fuel 120, 158-162 (2014).

18. Pardo, I. \& Camarero, S. Exploring the Oxidation of Lignin-Derived Phenols by a Library of Laccase Mutants. Molecules 20, 15929-15943 (2015).

19. Pardo, I. et al. Re-designing the substrate binding pocket of laccase for enhanced oxidation of sinapic acid. Catal. Sci. Technol. 6, 3900-3910 (2016).

20. Pardo, I., Chanagá, X., Vicente, A. I., Alcalde, M. \& Camarero, S. New colorimetric screening assays for the directed evolution of fungal laccases to improve the conversion of plant biomass. BMC Biotechnol. 13, 90 (2013).

21. Rodríguez-Escribano, D., de Salas, F., Pardo, I. \& Camarero, S. High-Throughput Screening Assay for Laccase Engineering toward Lignosulfonate Valorization. Int. J. Mol. Sci. 18 (2017).

22. Camarero, S. et al. Engineering platforms for directed evolution of Laccase from Pycnoporus cinnabarinus. Appl. Environ. Microbiol. 78, 1370-1384 (2012)

23. García-Ruiz, E., Maté, D., Ballesteros, A., Martinez, A. T. \& Alcalde, M. Evolving thermostability in mutant libraries of ligninolytic oxidoreductases expressed in yeast. Microb. Cell Fact. 9, 17 (2010).

24. Maté, D. et al. Laboratory evolution of high-redox potential laccases. Chem. Biol. 17, 1030-1041 (2010). 
25. Mateljak, I., Tron, T. \& Alcalde, M. Evolved $\alpha$-factor prepro-leaders for directed laccase evolution in Saccharomyces cerevisiae. Microb. Biotechnol. 10, 1830-1836 (2017).

26. Rakestraw, J. A., Sazinsky, S. L., Piatesi, A., Antipov, E. \& Wittrup, K. D. Directed evolution of a secretory leader for the improved expression of heterologous proteins and full-length antibodies in Saccharomyces cerevisiae. Biotechnol. Bioeng. 103, 1192-1201 (2009).

27. Li, G. et al. Simultaneous engineering of an enzyme's entrance tunnel and active site: the case of monoamine oxidase MAO-N. Chem. Sci. 8, 4093-4099 (2017).

28. Nguyen, Q.-T. et al. Structure-based engineering of Phanerochaete chrysosporium alcohol oxidase for enhanced oxidative power towards glycerol. Biochemistry. https://doi.org/10.1021/acs.biochem.8b00918 (2018)

29. Alcalde, M., Zumárraga, M., Polaina, J., Ballesteros, A. \& Plou, F. J. Combinatorial saturation mutagenesis by in vivo overlap extension for the engineering of fungal laccases. Comb. Chem. High. Throughput Screen. 9, 719-727 (2006).

30. Lunt, M. W. \& Snow, C. D. A Structure-Based Design Protocol for Optimizing Combinatorial Protein Libraries. Methods Mol. Biol. 1414, 99-138 (2016).

31. Gao, H. et al. A novel cold-adapted esterase from Enterobacter cloacae: Characterization and improvement of its activity and thermostability via the site of Tyr193Cys. Microb. Cell Fact. 17, 45 (2018).

32. Xu, G. et al. Expression of a thermo- and alkali-philic fungal laccase in Pichia pastoris and its application. Protein Expr. Purif. 154, 16-24 (2019)

33. Zhao, J., Zeng, S., Xia, Y. \& Xia, L. Expression of a thermotolerant laccase from Pycnoporus sanguineus in Trichoderma reesei and its application in the degradation of bisphenol A. J. Biosci. Bioeng. 125, 371-376 (2018).

34. Kiiskinen, L.-L. et al. Expression of Melanocarpus albomyces laccase in Trichoderma reesei and characterization of the purified enzyme. Microbiology 150, 3065-3074 (2004).

35. Mate, D. M. et al. Switching from blue to yellow: altering the spectral properties of a high redox potential laccase by directed evolution. Biocatal. Biotransform 31, 8-21 (2013).

36. Iimura, Y., Sonoki, T. \& Habe, H. Heterologous expression of Trametes versicolor laccase in Saccharomyces cerevisiae. Protein Expr. Purif. 141, 39-43 (2018).

37. Kittl, R. et al. A chloride tolerant laccase from the plant pathogen ascomycete Botrytis aclada expressed at high levels in Pichia pastoris. J. Biotechnol. 157, 304-314 (2012).

38. Mtibaà, R. et al. Purification and characterization of a fungal laccase from the ascomycete Thielavia sp. and its role in the decolorization of a recalcitrant dye. Int. J. Biol. Macromol. 120, 1744-1751 (2018).

39. Strzelecki, B., Romanowska, I., Bielecki, S. \& Marchut-Mikołajczyk, O. Sposób biosolubilizacji węgla brunatnego przy pomocy mikroorganizmów. Method of biosolubilization of brown coal in order to obtain organic fertilizer with high content of humic acids. Polish Patent Application P.423511 (2017).

40. Comba, P. \& Remenyi, R. A new molecular mechanics force field for the oxidized form of blue copper proteins. J. Comput. Chem. 23, 697-705 (2002)

41. Stewart, J. J. P. Optimization of parameters for semiempirical methods. J. Comput. Chem. 10, 209-220 (1989).

42. Li, H., Robertson, A. D. \& Jensen, J. H. Very fast empirical prediction and rationalization of protein pKa values. Proteins 61, 704-721 (2005).

43. Mahoney, M. W. \& Jorgensen, W. L. A five-site model for liquid water and the reproduction of the density anomaly by rigid, nonpolarizable potential functions. J. Chem. Phys. 112, 8910-8922 (2000).

44. Salomon-Ferrer, R., Case, D. A. \& Walker, R. C. An overview of the Amber biomolecular simulation package. Wiley Interdiscip. Rev. Comput. Mol. Sci. 3, 198-210 (2013).

45. Chemical Computing Group ULC. Molecular Operating Environment (MOE). (2018)

46. Halgren, T. A. \& Nachbar, R. B. Merck molecular force field. IV. conformational energies and geometries for MMFF94-Halgren1996-Journal of Computational Chemistry-Wiley Online Library. J. Comput. Chem. 17, 587-615 (1996).

47. Wang, J., Wolf, R. M., Caldwell, J. W., Kollman, P. A. \& Case, D. A. Development and testing of a general amber force field. J. Comput. Chem. 25, 1157-1174 (2004).

48. Hornak, V. et al. Comparison of multiple Amber force fields and development of improved protein backbone parameters. Proteins 65, 712-725 (2006).

49. Darden, T., York, D. \& Pedersen, L. Particle mesh Ewald: An N.log(N) method for Ewald sums in large systems. J. Chem. Phys. 98, 10089-10092 (1993)

50. Humphrey, W., Dalke, A. \& Schulten, K. VMD: Visual molecular dynamics. J. Mol. Graph. 14, 33-38 (1996).

51. Dassault Systèmes BIOVIA, Discovery Studio Modeling Environment, Release 2017, San Diego: Dassault Systèmes, 2016.

52. Miller, B. R. et al. MMPBSA.py: An Efficient Program for End-State Free Energy Calculations. J. Chem. Theory Comput. 8, 3314-3321 (2012).

53. Bendl, J. et al. HotSpot Wizard 2.0: automated design of site-specific mutations and smart libraries in protein engineering. Nucleic Acids Res. 44, W479-487 (2016).

\section{Acknowledgements}

We would like to thank Dr. Miguel Alcalde and Dr. David Gonzalez-Perez for the scientific discussions that helped us during this study. We also thank Bartosz Strzelecki for providing biosolubilized coal. This study was funded by National Science Centre, Poland (Preludium, 2015/19/N/NZ9/01648).

\section{Author contributions}

N.K. performed the experiments, analyzed the data and prepared the manuscript. M.J.K. cooperated on data analysis and manuscript preparation. A.K., A.D. and P.P. contributed to molecular simulation studies and manuscript preparation. S.B. initiated the project and supervised the work. All authors read and approved the final manuscript.

\section{Competing interests}

The authors declare no competing interests.

\section{Additional information}

Supplementary information is available for this paper at https://doi.org/10.1038/s41598-020-60204-1.

Correspondence and requests for materials should be addressed to S.B.

Reprints and permissions information is available at www.nature.com/reprints. 
Publisher's note Springer Nature remains neutral with regard to jurisdictional claims in published maps and institutional affiliations.

(c) (i) Open Access This article is licensed under a Creative Commons Attribution 4.0 International License, which permits use, sharing, adaptation, distribution and reproduction in any medium or format, as long as you give appropriate credit to the original author(s) and the source, provide a link to the Creative Commons license, and indicate if changes were made. The images or other third party material in this article are included in the article's Creative Commons license, unless indicated otherwise in a credit line to the material. If material is not included in the article's Creative Commons license and your intended use is not permitted by statutory regulation or exceeds the permitted use, you will need to obtain permission directly from the copyright holder. To view a copy of this license, visit http://creativecommons.org/licenses/by/4.0/.

(c) The Author(s) 2020 